\title{
Chain transfer to solvent in the radical polymerization of structurally diverse acrylamide monomers using straight-chain and branched alcohols as solvents
}

\author{
Christopher Magee, ${ }^{a}$ Yusuke Sugihara, ${ }^{b}$ Per B. Zetterlund ${ }^{* b}$ and Fawaz Aldabbagh ${ }^{* a}$
}

\begin{abstract}
Chain transfer to solvent in conventional radical polymerizations of $N$-tert-butylacrylamide (TBAM) and $N$-(2-morpholin-4-ylethyl) acrylamide (MEA) in a range of alcohol solvents is investigated. Mayo analysis of polymerization of TBAM in linear alcohols $\left(\mathrm{C}_{3}-\mathrm{C}_{9}\right)$ resulted in an approximately linear increase in chain transfer to solvent constant $\left(C_{\mathrm{tr}, \mathrm{S}}\right)$ with the number of methylene $\left(\mathrm{CH}_{2}\right)$ units in the solvent. The branched alcohol 3-methyl-3-pentanol gave the smallest $C_{\mathrm{tr}, \mathrm{S}}$ (using Mayo analysis), and thus allowed attainment of higher molecular weights (MWs) in the nitroxide-mediated polymerizations (NMP) of TBAM. Overall, the data show that MEA is more prone to chain transfer to solvent than TBAM (higher $C_{\mathrm{tr}, \mathrm{S}}$ ), and further analysis of the conventional radical polymerization of MEA in 3methyl-3-pentanol indicate chain transfer to monomer may also be occurring. The first controlled/living polymerizations of MEA are detailed with chain transfer having a greater impact on maximum achievable MWs in NMP in comparison to TBAM.
\end{abstract}

\section{INTRODUCTION}

Chain transfer to solvent or monomer is the abstraction of an atom by a propagating radical to give a dead polymer chain and a small radical capable of initiating a new chain. For a given set of conditions, chain transfer results in an upper limit in accessible molecular weight for both a conventional ${ }^{[1]}$ and controlled/living radical polymerization (CLRP). In a recent report, ${ }^{[2]}$ chain transfer to solvent was shown to be a significant end-forming reaction in the conventional and nitroxide-mediated polymerization (NMP) ${ }^{[3]}$ of $N$ isopropylacrylamide (NIPAM) in DMF at $120^{\circ} \mathrm{C}$.
The same chain transfer to solvent constant $\left(C_{\mathrm{tr}, \mathrm{S}}=k_{\mathrm{tr}, \mathrm{S}} / k_{\mathrm{p}}\right.$, the ratio between the rate coefficients for chain transfer to solvent and propagation), within experimental error, was shown to account for experimental molecular weight (MW) data for both conventional radical polymerization and NMP. In the case of CLRP, chain transfer can compromise both control and livingness by generation of dead chains (loss of propagating radicals) and accumulation of short chains (due to reinitiation) that give low MW tailing or broadening in the MW distribution (MWD) with increasing conversion. ${ }^{[4-8]}$
${ }^{a}$ School of Chemistry, National University of Ireland Galway, University Road, Galway, Ireland.

${ }^{b}$ Centre for Advanced Macromolecular Design (CAMD), School of Chemical Engineering, The University of New South Wales, Sydney, NSW 2052, Australia.
Corresponding authors:

E-mail: p.zetterlund@unsw.edu.au; Tel: +61 293856250 \&

fawaz.aldabbagh@nuigalway.ie; Tel: +35391493120

Electronic supplementary information (ESI) available: Rate plots and molecular weight distributions for NMP. 
In the case of chain transfer to solvent, it has been shown that as a consequence of the total number of chains increasing, the number average molecular weight $\left(M_{\mathrm{n}}\right)$ deviates downwards from the theoretical value $\left(M_{\mathrm{n}, \mathrm{th}}\right)$ and may even decrease with increasing conversion, which is distinctly different from chain transfer to monomer where theory dictates that $M_{\mathrm{n}}$ never goes through a maximum. ${ }^{[2,9]}$ The value of $M_{\mathrm{n}}$ going through a maximum with increasing conversion has also been observed in the NMP of acrylic acid using 1,4-dioxane as solvent at $120{ }^{\circ} \mathrm{C} .{ }^{[10]}$ Chain transfer to solvent has been detected in other CLRPs, for example causing a limiting $M_{\mathrm{n}}$ in the reversible addition-fragmentation chain transfer $(\mathrm{RAFT})^{[11]}$ polymerization of acrylic acid at $80{ }^{\circ} \mathrm{C}$ in ethanol, 2propanol and 1,4-dioxane ${ }^{[12]}$ and RAFT of hydrophobic acrylamide monomers at $90{ }^{\circ} \mathrm{C}$ in DMF and 1,4-dioxane. ${ }^{[13]}$

Chain transfer to solvent should be a fundamental consideration when polymerizing monomers that are solids, and thus are not polymerized in bulk, but rather in solutions of organic solvents. NIPAM is such a monomer (a solid with m.p. 60-63 ${ }^{\circ} \mathrm{C}$ ), which is commonly polymerized in solution. The inverse suspension NMP of NIPAM in supercritical carbon dioxide has been reported, ${ }^{[14]}$ in which case $M_{\mathrm{n}}$ did not deviate significantly from $M_{\mathrm{n}, \mathrm{th}}$ consistent with chain transfer to $\mathrm{CO}_{2}$ (as well as chain transfer to monomer) being negligible.

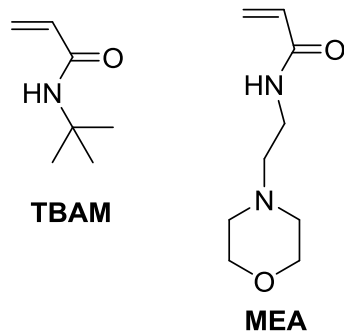

Scheme 1. Acrylamide monomers used: $N$-tert-butylacrylamide (TBAM) and $N$-(2-morpholin-4-ylethyl) acrylamide (MEA).

We now report on chain transfer to solvent in the conventional radical polymerization of two alternative solid acrylamide monomers (Scheme 1) using various straight chain and branched alcohol solvents. $N$-(2-morpholin-4-ylethyl)acrylamide (MEA; m.p. $114{ }^{\circ} \mathrm{C}$ ) and $N$-tert-butylacrylamide (TBAM; m.p. 126-129 ${ }^{\circ} \mathrm{C}$ ) have important biotechnological applications. TBAM is a hydrophobic monomer often used as a comonomer to reduce the lower critical solution temperature (LCST) of poly(NIPAM). ${ }^{[15-17]}$ MEA is less exploited, but has an ionisable heterocyclic substituent, which as a polymer can be used to complex with biomolecules such as DNA in potential non-viral gene vectors. ${ }^{[18,19]}$ The first CLRP of MEA is disclosed, and we examine the significance of chain transfer in limiting the controlled/living character in the NMP of this monomer. Alcohols were chosen as solvents since there are no systematic studies reported comparing $C_{\text {trs }}$ with incremental differences in solvent chemical structure. The relationship between the extent of chain transfer to solvent for these two diverse acrylamides and the chemical structure of the alcohol solvent is detailed with the magnitude of the $C_{\mathrm{tr}, \mathrm{S}}$ related to solvent suitability for NMP. All molecular weight measurements were conducted relative to linear polystyrene standards, and as such the $C_{\mathrm{tr}, \mathrm{s}}$ values reported in this work are not absolute should be treated with caution.

\section{EXPERIMENTAL}

\section{Materials}

tert-Butyl acrylate ( $t$-BA, Aldrich, 98\%) was purified by distillation under reduced pressure to remove inhibitors. $\mathrm{N}$-tert-butylacrylamide (TBAM, TCI, 98\%) was recrystallized from 1:1 benzene/acetone before use. 2,2'-Azobisisobutyronitrile and 1,1'azobis(cyclohexanecarbonitrile) (AIBN and ACN, DuPont Chemical Solution Enterprise) were recrystallized from $\mathrm{MeOH}$ before use, and tert-butyl peroxide (TBP, Aldrich, 98\%) was used as received. 1Propanol (Aldrich, 99\%), 1-butanol (TCI, 99\%), 1-pentanol (Aldrich, 99\%), 1-hexanol (Aldrich, 98\%), 1-heptanol (Aldrich, 99\%), 1-octanol (Aldrich, 99\%), 1-nonanol (Aldrich, 99\%), 2ethylbutanol (Aldrich, 98\%) and 3-methyl-3-pentanol (TCI, 98\%) were used as received. $N$-tert-butyl- $N$-[1-diethylphosphono(2,2dimethylpropyl)]oxy $\quad(\mathrm{SG} 1)^{[20]}$ and $N$-(2-morpholin-4-ylethyl) acrylamide (MEA) ${ }^{[21]}$ were prepared according to the literature, and SG1 was purified by column chromatography with purity $(95 \%)$ determined using ${ }^{1} \mathrm{H}$ NMR spectroscopy from reaction of SG1 radical with pentafluorophenylhydrazine (Aldrich, 97\%).

\section{Measurements}

Number-average molecular weight $\left(M_{\mathrm{n}}\right)$ and polydispersity $\left(M_{\mathrm{w}} / M_{\mathrm{n}}\right)$ were determined using a gel permeation chromatography (GPC) system consisting of a Viscotek DM 400 data manager, a Viscotek VE 3580 refractive-index detector and two Viscotek Viscogel $\mathrm{GMH}_{\mathrm{HR}}-\mathrm{M}$ columns. Measurements were carried out at $60{ }^{\circ} \mathrm{C}$ at a flow rate of $1.0 \mathrm{~mL} \mathrm{~min}^{-1}$ using HPLC-grade DMF containing 0.01 $\mathrm{M} \mathrm{LiBr}$ as the eluent. The columns were calibrated using twelve 
poly(styrene) standards $\left(M_{\mathrm{n}}=580-6,035,000 \mathrm{~g} \mathrm{~mol}^{-1}\right) \cdot M_{\mathrm{n}}$ is given in $\mathrm{g} \mathrm{mol}^{-1}$ throughout. The use of poly(styrene) standards inevitably leads to an error in molecular weights - as such the $C_{\mathrm{tr}, \mathrm{S}}$ data reported also contains a comparable error. ${ }^{1} \mathrm{H}$ NMR spectra were recorded using a Joel GXFT $400 \mathrm{MHz}$ instrument equipped with a DEC AXP 300 computer workstation. For conversion measurement each spectrum received a total of 16 scans with relaxation delay of $1 \mathrm{~s}$ and repetition time of $3.18 \mathrm{~s}$. The signal to noise is higher than 1000:1 with integration errors of less than 1\%. Using TBAM in 1propanol or 1-hexanol as solvent, conversions were measured by GC using a Shimadzu GC-8A Gas Chromatograph. For all other polymerizations of TBAM, conversions were measured by gravimetry by removal of solvent under reduced pressure, dissolving the residue in a minimum amount of DMF, and precipitating the polymer from distilled water. Polymers were dried under vacuum for several days at room temperature prior to conversion measurement. Conversions for both conventional radical polymerization and NMP of MEA were measured using ${ }^{1} \mathrm{H}$ NMR by comparing the integral of the peak at 3.20-3.90 ppm $\left(\mathrm{OCH}_{2}, 1-\mathrm{CH}_{2}\right.$, $6 \mathrm{H})$, which contains both poly(MEA) and MEA monomer contributions with the vinyl peak of the monomer at $5.65 \mathrm{ppm}$ $(=\mathrm{CH}-, 1 \mathrm{H})$.

\section{Synthesis of Macroinitiators}

Macroinitiators were prepared by precipitation NMP in supercritical carbon dioxide. $^{[22]}$ Two batches of poly( $t$-BA)-SG1 $\left(M_{\mathrm{n}}=3,700\right.$, $\left.M_{\mathrm{w}} / M_{\mathrm{n}}=1.20 ; M_{\mathrm{n}}=5,000, \quad M_{\mathrm{w}} / M_{\mathrm{n}}=1.18\right)$ were used as macroinitiator for NMP of TBAM in various alcohols, and poly $(t$ BA)-SG1 with $M_{\mathrm{n}}=8,300$ and $M_{\mathrm{w}} / M_{\mathrm{n}}=1.25$ was used for NMP of MEA in 3-methyl-3-pentanol. The $M_{\mathrm{n}}$ and $M_{\mathrm{w}} / M_{\mathrm{n}}$ were measured using the above GPC conditions.

\section{General Polymerization Procedure}

All polymerization mixtures were added to Pyrex ampoules and subjected to several freeze-degas-thaw cycles to remove oxygen before sealing under vacuum. The ampoules were heated at a specific temperature in an aluminium heating block for various times. Polymerizations were stopped by placing ampoules in an icewater bath.
Conventional Radical Polymerizations at low Initiator Concentrations

A typical procedure is as follows: Stock solutions containing, 0.41, 1.4, 2.5 and $4.1 \mathrm{mM}$ of TBP were made up in 1-propanol. Stock solution $(1 \mathrm{~mL})$ was added to MEA $(0.3685 \mathrm{~g}, 2.00 \mathrm{mmol})$ in a Pyrex ampoule. Evacuated ampoules were heated at $120{ }^{\circ} \mathrm{C}$ for various times.

\section{Estimating Chain Transfer Constants using Mayo Plots}

A typical procedure is as follows: Stock solution of TBP $(0.41 \mathrm{mM})$ in 1-hexanol (1 mL, $7.96 \mathrm{mmol})$ was added to MEA (0.293 g, 1.59 mmol; $0.147 \mathrm{~g}, 0.8 \mathrm{mmol} ; 0.098 \mathrm{~g}, 0.53 \mathrm{mmol}$ and $0.073 \mathrm{~g}, 0.40$ mmol to give $[\text { Solvent }]_{0} /[\text { Monomer }]_{0}=5,10,15$ and 20). Evacuated ampoules were heated at $120{ }^{\circ} \mathrm{C}$ for various times. Conversions were less than $10 \%$ in all cases.

\section{Nitroxide-Mediated Polymerization (NMP) of TBAM using Macroinitiators}

A typical procedure is as follows: The following NMPs were carried out using stock solutions of 1-hexanol and 3-methyl-3-pentanol containing SG1 $\left(1.67 \times 10^{-3} \mathrm{mM}\right)$. Stock solutions $(1 \mathrm{~mL})$ were added to TBAM $(0.2544 \mathrm{~g}, 2.00 \mathrm{mmol})$ and poly $(t$-BA)-SG1 (0.033 $\left.\mathrm{g}, 6.67 \times 10^{-3} \mathrm{mmol}\right)$ to give $[\mathrm{TBAM}]_{0} /[\operatorname{poly}(t \mathrm{BA})-\mathrm{SG} 1]_{0}=300$, and heated at $120{ }^{\circ} \mathrm{C}$ for various times.

\section{NMP of MEA using SG1/AIBN and Macroinitiator Initiation}

\section{Systems}

NMP was carried out using a stock solution containing AIBN (9.03 x $\left.10^{-3} \mathrm{mM}\right)$ and SG1 $\left(2.26 \times 10^{-2} \mathrm{mM}\right)$ in 1-propanol or 1-hexanol. Stock solution $(1 \mathrm{~mL})$ was added to MEA $(0.3685 \mathrm{~g}, 2.00 \mathrm{mmol})$ to give $[\mathrm{MEA}]_{0} /[\mathrm{AIBN}]_{0}=222$, and heated at $120{ }^{\circ} \mathrm{C}$ for various times. For macroinitiator-initiated NMP, stock solution containing SG1 (2.25 x 10-3 $\mathrm{mM})$ in 3-methyl-3-pentanol was prepared. Stock solution $(1 \mathrm{~mL})$ was added to MEA $(0.3685 \mathrm{~g}, 2.00 \mathrm{mmol})$ and $\operatorname{poly}\left(t\right.$-BA)-SG1 $\quad\left(55.4 \mathrm{mg}, \quad 6.67 \times \quad \times \quad 10^{-3} \mathrm{mmol}\right)$ to give $[\mathrm{MEA}]_{0} /[\operatorname{poly}(t-\mathrm{BA})-\mathrm{SG} 1]_{0}=300$, and heated at $120{ }^{\circ} \mathrm{C}$ for various times.

\section{Spontaneous Initiation of MEA in the Absence of Initiator or} Nitroxide

Evacuated ampoules containing MEA (0.3685 g, $2.00 \mathrm{mmol})$ in 1propanol $(1 \mathrm{~mL})$ were heated at $120^{\circ} \mathrm{C}$ for various times. 


\section{RESULTS AND DISCUSSION}

\section{Conventional Radical Polymerizations}

Conventional radical polymerizations of TBAM were carried out using very low rates of initiation in 1-propanol at $120{ }^{\circ} \mathrm{C}$. When the propagating radical concentration is sufficiently low, the rate of bimolecular termination is minimized to the extent that chain transfer to monomer or solvent becomes the main end-forming event. ${ }^{[1]}$ Figure 1a shows that the MWDs obtained for the three different initiator concentrations are essentially superimposed with $M_{\mathrm{n}}=36,900$ and $M_{\mathrm{w}} / M_{\mathrm{n}}=1.69\left([\mathrm{TBP}]_{0}=4.1 \mathrm{mM}\right), M_{\mathrm{n}}=39,950$ and $M_{\mathrm{w}} / M_{\mathrm{n}}=1.60([\mathrm{TBP}]=1.4 \mathrm{mM})$, and $M_{\mathrm{n}}=41,400$ and $M_{\mathrm{w}} / M_{\mathrm{n}}$ $=1.68([\mathrm{TBP}]=0.41 \mathrm{mM})$, consistent with chain transfer dictating the maximum attainable molecular weight. If chain transfer to a small molecule is the main end-forming event, theory dictates that $M_{\mathrm{w}} / M_{\mathrm{n}}=2$, and as such it is surprising that $M_{\mathrm{w}} / M_{\mathrm{n}}<2$ in these cases. However, it has been reported that GPC calibration error (i.e. use of inappropriate polymer standards) can cause artificial narrowing of the MWD. ${ }^{[23,24]}$ Comparative polymerizations of MEA in 1-propanol at $120{ }^{\circ} \mathrm{C}$ were carried out, once again resulting in very similar MWDs (Figure 1b) with $M_{\mathrm{n}}=12,900$ and $M_{\mathrm{w}} / M_{\mathrm{n}}=2.02$ $\left([\mathrm{TBP}]_{0}=4.1 \mathrm{mM}\right), M_{\mathrm{n}}=13,900$ and $M_{\mathrm{w}} / M_{\mathrm{n}}=2.03\left([\mathrm{TBP}]_{0}=2.5\right.$ $\mathrm{mM}), M_{\mathrm{n}}=15,000$ and $M_{\mathrm{w}} / M_{\mathrm{n}}=1.93([\mathrm{TBP}]=1.4 \mathrm{mM})$, and $M_{\mathrm{n}}=$ 14,700 and $M_{\mathrm{w}} / M_{\mathrm{n}}=2.04([\mathrm{TBP}]=0.41 \mathrm{mM})$. The maximum $D P_{\mathrm{n}}$ $(<82)$ reached is considerably less than for the analogous TBAM $(<$ 326) polymerizations, indicating the poly(MEA) propagating radical is more susceptible to chain transfer (assuming similar $k_{\mathrm{p}}$ values).

The value of $C_{\mathrm{tr}, \mathrm{S}}$ in the conventional radical polymerization of TBAM at $120{ }^{\circ} \mathrm{C}$ using a variety of alcohols as solvents was estimated based on the classical Mayo equation:

$$
\frac{1}{D P_{\mathrm{n}}}=\frac{1}{D P_{\mathrm{n}, 0}}+C_{\mathrm{tr}, \mathrm{S}} \frac{[\text { Solvent }]}{[\text { Monomer }]}
$$

where $D P_{\mathrm{n}}$ denotes the number-average degree of polymerization and the subscript 0 denotes $D P_{\mathrm{n}}$ in the absence of chain transfer agent (solvent). The value of $C_{\mathrm{tr}, \mathrm{S}}$ is obtained as the slope of a plot of $1 / D P_{\mathrm{n}}$ versus [Solvent]/[Monomer] (Figure 2, Table 1).
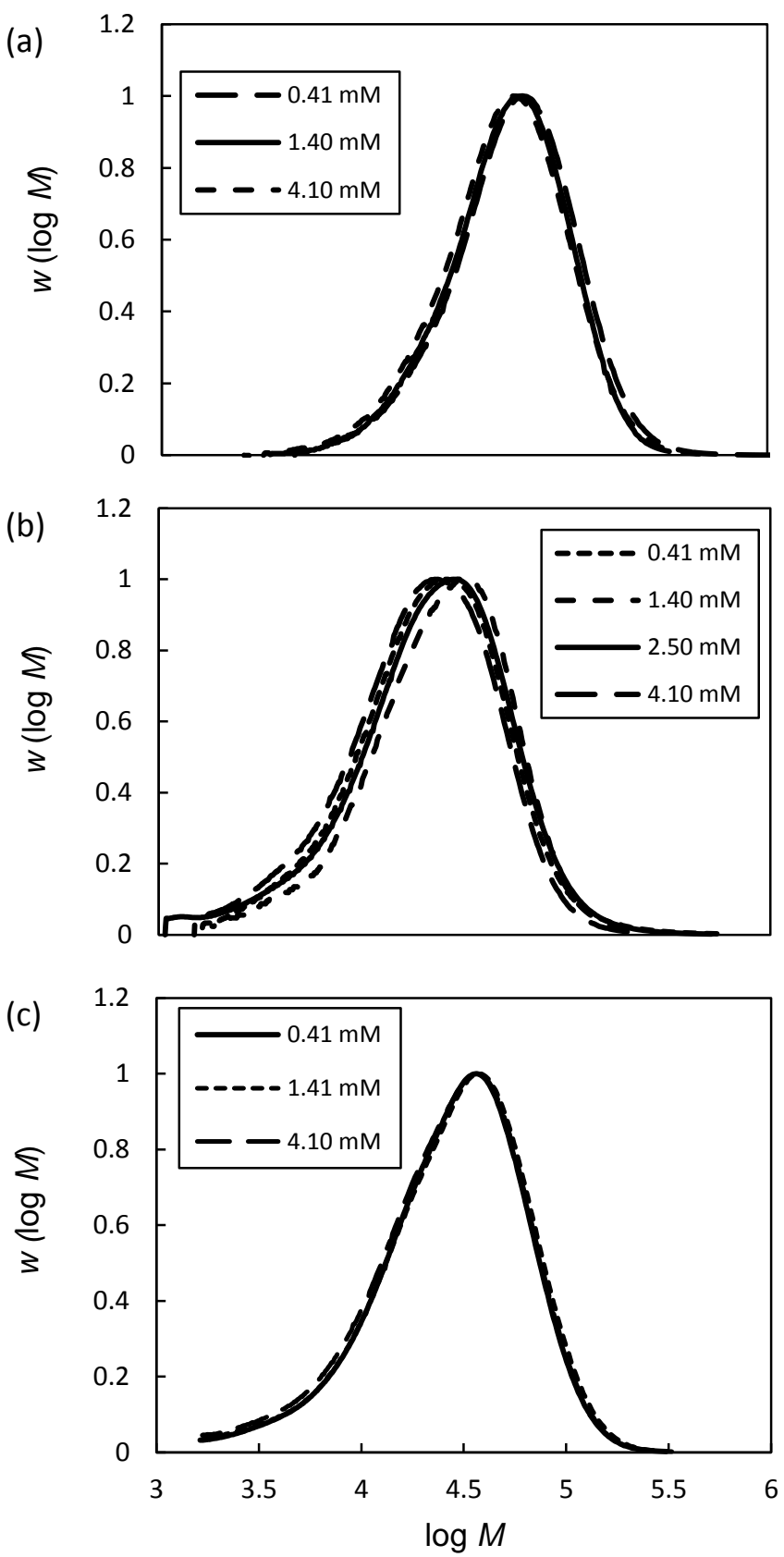

Figure 1. MWDs for the conventional radical polymerizations of 2 $\mathrm{M}$ TBAM and MEA at $120{ }^{\circ} \mathrm{C}$ using the shown initiator (TBP) concentrations; (a) TBAM polymerizations in 1-propanol, 8 (0.41 $\mathrm{mM}), 21(1.4 \mathrm{mM})$ and $32 \%(4.1 \mathrm{mM})$ conversion. (b) MEA polymerizations in 1-propanol, 5 (0.41 mM), 16 (1.4 mM), 14 (2.5 $\mathrm{mM}$ ) and $10 \%(4.1 \mathrm{mM})$ conversion. (c) MEA polymerizations in 3methyl-3-pentanol, $10(0.41 \mathrm{mM}), 6(1.4 \mathrm{mM})$ and $20 \%(4.1 \mathrm{mM})$ conversion. 
The $C_{\mathrm{tr}, \mathrm{S}}$ values for TBAM from Figure $2 \mathrm{a}$ obtained for straight chain (linear) alcohols 1-propanol to 1-nonanol were then plotted versus the number of carbons $(n)$ in the alcohol (Figure 3 ). An approximately linear increase in $C_{\mathrm{tr}, \mathrm{S}}$ is observed with the number of carbons in the linear alcohols $\mathrm{C}_{3}-\mathrm{C}_{9}$. Since each alcohol differs from the next by a methylene unit $\left(\mathrm{CH}_{2}\right)$, the extent of chain transfer to solvent for TBAM is dictated by the relative number of $\mathrm{CH}_{2}$ units in the alcohol solvent (assuming $k_{\mathrm{p}}$ is not significantly influenced by the solvent). The $C_{\mathrm{tr}, \mathrm{S}}$ for TBAM increases approximately 3-fold from 1-propanol to 1-nonanol.

$C_{\mathrm{tr}, \mathrm{S}}$ in conventional radical polymerizations of MEA in various alcohol solvents at $120{ }^{\circ} \mathrm{C}$ were also estimated by Mayo analysis (Figure 2c), resulting in $C_{\mathrm{tr}, \mathrm{S}}$ values a factor of two or greater than for TBAM (Figure 3). The incremental increase in $C_{\mathrm{tr}, \mathrm{S}}$ for the straight chain alcohols is somewhat less pronounced for MEA than TBAM. $C_{\mathrm{tr}, \mathrm{S}}$ for MEA in straight chain alcohols was $1.4 \times 10^{-3}, 1.5 \mathrm{x}$ $10^{-3}$ and $1.8 \times 10^{-3}$ compared to $C_{\mathrm{tr}, \mathrm{S}}$ for TBAM of $3.6 \times 10^{-4}, 6.5 \times$ $10^{-4}$ and $9.3 \times 10^{-4}$ in 1-propanol, 1-hexanol and 1-octanol, respectively (Table 1 ).

The effect of branching in the alcohol solvent was next investigated by carrying out conventional radical polymerizations of TBAM in isomers of $\mathrm{C}_{6} \mathrm{H}_{13} \mathrm{OH}$ (Scheme 2). $C_{\mathrm{tr}, \mathrm{S}}$ was estimated using the analogous Mayo conditions (Figure 2b), and again shown to increase with the number of methylene units; 3-methyl-3-pentanol $\left(2.2 \times 10^{-4}\right)$, 2-ethyl-1-butanol $\left(5.7 \times 10^{-4}\right)$ and 1-hexanol $\left(6.5 \times 10^{-4}\right)$ (Table S1). The $C_{\mathrm{tr}, \mathrm{S}}$ in 2-ethyl-1-butanol is perhaps larger than expected by considering only the relative number of methylene units - this is due to the readily abstractable methine $(\mathrm{CH})$ hydrogen, which would result in a stable tertiary radical. Chain transfer to methyl isobutyrate, which also generates a tertiary radical, has previously been detected by mass spectrometry in the radical polymerization of methyl methacrylate. ${ }^{[25]}$

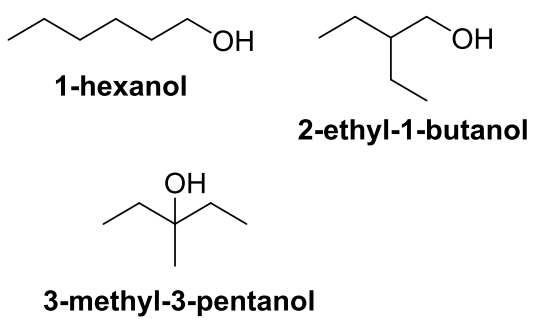

Scheme 2 Structural isomers of $\mathrm{C}_{6} \mathrm{H}_{13} \mathrm{OH}$ used as solvents.
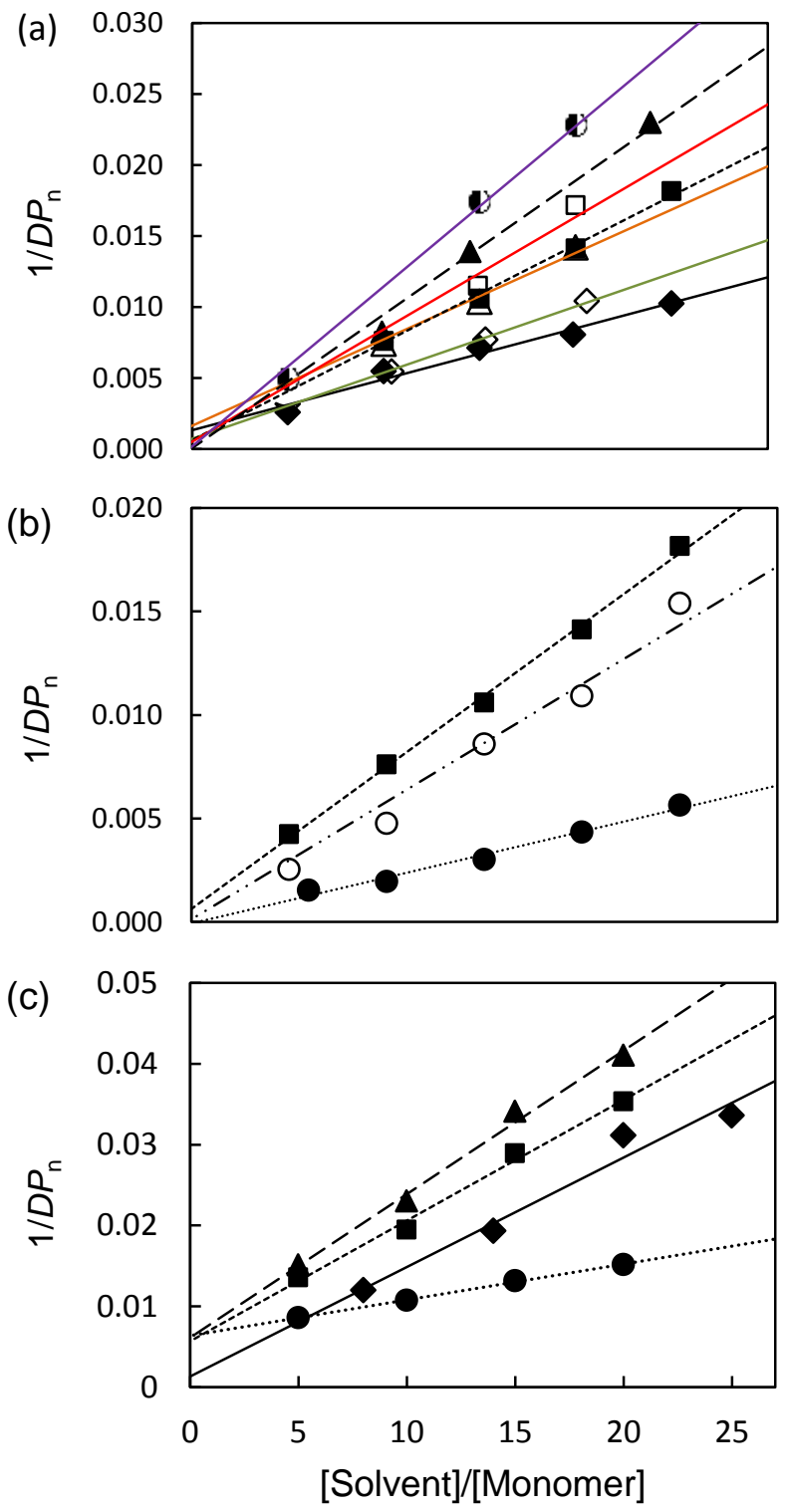

Figure 2. Mayo plots for conventional radical polymerizations of 2 M TBAM and MEA initiated by TBP $(0.41 \mathrm{mM})$ at $120{ }^{\circ} \mathrm{C}$ in various alcohols; (a) TBAM in 1-propanol ( $\downarrow$, solid line), 1-butanol $(\diamond$, green line), 1-pentanol ( $\Delta$, brown line), 1-hexanol ( $\square$, short dashed line), 1-heptanol ( $\square$, red line), 1-octanol ( $\boldsymbol{\Delta}$, long dashed line) and 1-nonanol (O, purple line) as solvents (b) TBAM in isomers of $\mathrm{C}_{6} \mathrm{H}_{13} \mathrm{OH}$; 1-hexanol (a, short dashed line), 2-ethyl-1butanol ( $\circ$, dashed-dotted line), and 3-methyl-3-pentanol (•, dotted line) as solvents (c) MEA in various alcohols; 1-propanol ( $\downarrow$, solid line), 1-hexanol ( $\mathbf{m}$, short dashed line), 1-octanol ( $\boldsymbol{\Delta}$, long dashed line) and 3-methyl-3-pentanol $(\bullet$, dotted line) as solvents. 


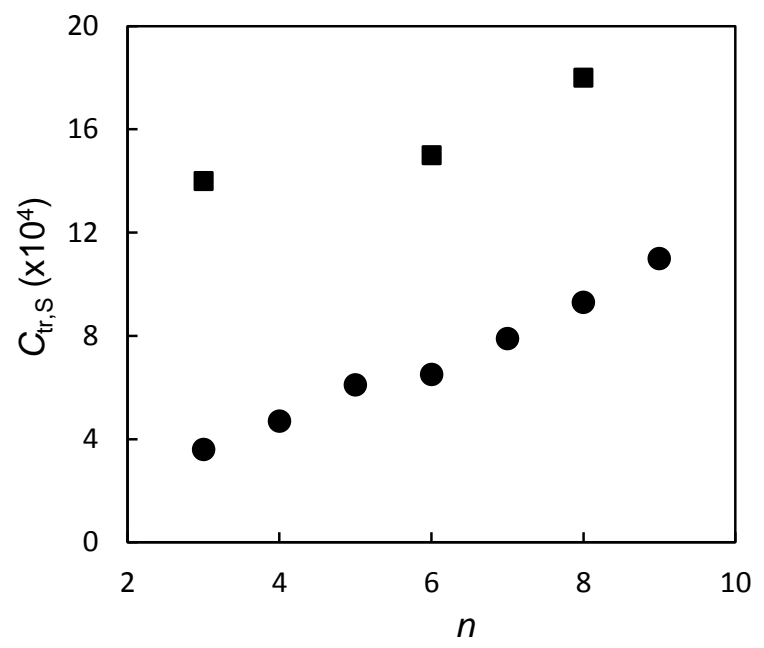

Figure 3. Chain transfer to solvent constant $\left(C_{\mathrm{tr}, \mathrm{S}}\right)$ (estimated from Mayo plots) plotted versus the number of carbons $(n)$ in linear alcohols $\left(\mathrm{C}_{n} \mathrm{H}_{2 n+1} \mathrm{OH}\right)$ used as solvent for conventional radical polymerizations of $2 \mathrm{M} \mathrm{TBAM}(\bullet)$ and $\operatorname{MEA}(\bullet)$ at $120^{\circ} \mathrm{C}$.

Table 1. $C_{\mathrm{tr}, \mathrm{S}}$ coefficients obtained from the slope of Mayo plots (Figure 2) for conventional radical polymerizations of TBAM and MEA in various alcohols as solvents at $120{ }^{\circ} \mathrm{C}$ (all $C_{\mathrm{tr}, \mathrm{S}}$ values are based on linear polystyrene standards)

\begin{tabular}{lll}
\hline Monomer & Solvent & $\begin{array}{l}\boldsymbol{C}_{\text {tr. }} \text { from Mayo } \\
\text { plot (conv. rad. } \\
\text { polym.) }\end{array}$ \\
\hline TBAM & 1-propanol & $3.6 \times 10^{-4}$ \\
TBAM & 1-butanol & $4.7 \times 10^{-4}$ \\
TBAM & 1-pentanol & $6.1 \times 10^{-4}$ \\
TBAM & 1-hexanol & $6.5 \times 10^{-4}$ \\
TBAM & 1-heptanol & $7.9 \times 10^{-4}$ \\
TBAM & 1-octanol & $9.3 \times 10^{-4}$ \\
TBAM & 1-nonanol & $11.0 \times 10^{-4}$ \\
TBAM & 2-ethyl-1-butanol & $5.7 \times 10^{-4}$ \\
TBAM & 3-methyl-3-pentanol & $2.2 \times 10^{-4}$ \\
MEA & 1-propanol & $14.0 \times 10^{-4}$ \\
MEA & 1-hexanol & $15.0 \times 10^{-4}$ \\
MEA & 1-octanol & $18.0 \times 10^{-4}$ \\
MEA & 3-methyl-3-pentanol & $4.0 \times 10^{-4}$ \\
\hline
\end{tabular}

In order to investigate if significantly greater molecular weights could be achieved for the polymerization of MEA in 3-methyl-3pentanol, the solvent that had the lowest $C_{\mathrm{tr}, \mathrm{S}}$ with TBAM, analogous conventional radical polymerizations at low radical concentrations were carried out (Figure 1c). The resulting overlapping MWDs are indicative of chain transfer being the main end-forming reaction, although higher $M_{\mathrm{n}}$ values are indeed achieved (than for 1-propanol) because of the lower anticipated $C_{\mathrm{tr}, \mathrm{S}}$ with $M_{\mathrm{n}}=16,130$ and $M_{\mathrm{w}} / M_{\mathrm{n}}=2.10\left([\mathrm{TBP}]_{0}=4.1 \mathrm{mM}\right), M_{\mathrm{n}}=$ 17,990 and $M_{\mathrm{w}} / M_{\mathrm{n}}=2.09([\mathrm{TBP}]=1.4 \mathrm{mM})$, and $M_{\mathrm{n}}=17,260$ and $M_{\mathrm{w}} / M_{\mathrm{n}}=2.05([\mathrm{TBP}]=0.41 \mathrm{mM})$.

Assuming that chain transfer to solvent is the sole chain end forming event and that the solvent concentration remains constant at its initial value, $D P_{\mathrm{n}}$ (cumulative value) can be expressed as a function of conversion according to eq $2:^{[2]}$

$$
D P_{\mathrm{n}}=\frac{[\mathrm{M}]_{0}(2-\alpha)}{2[\mathrm{~S}]_{0} C_{\mathrm{tr}, \mathrm{S}}}
$$

where $[\mathrm{M}]_{0}$ and $[\mathrm{S}]_{0}$ represent initial monomer and solvent concentrations, and $\alpha$ denotes fractional monomer conversion. Fitting of eq 2 to a data set of $D P_{\mathrm{n}}$ vs conversion for a system where chain transfer to solvent is not the sole end forming event leads to overestimation of $C_{\mathrm{tr}, \mathrm{S}}$. The $M_{\mathrm{n}}$ data for the conventional radical polymerization of TBAM in 1-propanol at the three different (low) initiator concentrations in Figure 1a have been plotted versus conversion in Figure 4 . The data were subsequently fitted to eq 2 resulting in $C_{\mathrm{tr}, \mathrm{S}}=4.3 \times 10^{-4}$, which is close to the value of $C_{\mathrm{tr}, \mathrm{S}}=$ $3.6 \times 10^{-4}$ derived from the Mayo plot (Figure 3 and Table 1). The MWDs of Figure 1a may be influenced by chain transfer to solvent or monomer or both; however, the fact that the Mayo treatment (which gives $C_{\mathrm{tr}, \mathrm{S}}$ ) results in a value close to that from eq. 2 is consistent with chain transfer to solvent being the main end-forming event under these conditions. 


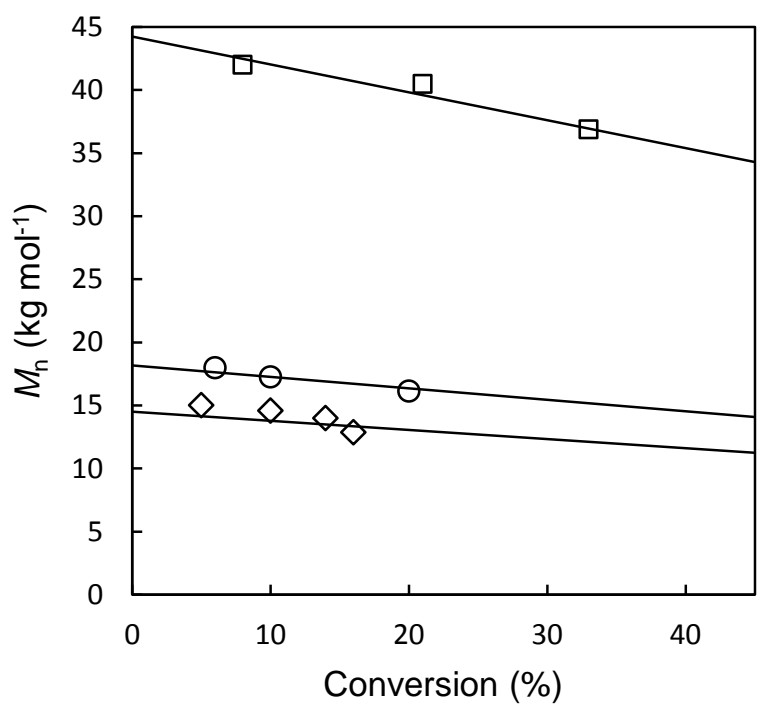

Figure 4. $M_{\mathrm{n}}$ versus conversion for conventional radical polymerizations of $2 \mathrm{M}$ TBAM in 1-propanol (口), MEA in 1propanol $(\diamond)$ and MEA in 3-methyl-3-pentanol (०) at $120{ }^{\circ} \mathrm{C}$ at different $[\mathrm{TBP}]_{0}$ corresponding to Figure 1 with full lines representing $M_{\mathrm{n}}$ calculated using eq 2 with $C_{\mathrm{tr}, \mathrm{S}}=4.3 \times 10^{-4}, 1.9 \mathrm{x}$ $10^{-3}$ and $2.5 \times 10^{-3}$ respectively.

The $M_{\mathrm{n}}$ data for the conventional radical polymerizations of MEA in 1-propanol (Figure 1b) and 3-methyl-3-pentanol (Figure 1c) at different (low) initiator concentrations were plotted versus conversion in Figure 4. Fitting with eq 2 resulted in $C_{\mathrm{tr}, \mathrm{S}}=1.9 \times 10^{-3}$ in 1-propanol, in relatively good agreement with $C_{\mathrm{tr}, \mathrm{S}}=1.4 \times 10^{-3}$ from the Mayo plot. In the case of 3-methyl-3-pentanol, $C_{\mathrm{tr}, \mathrm{S}}=2.5 \mathrm{x}$ $10^{-3}$ is derived by fitting eq 2 , which is more than six times greater than the $C_{\mathrm{tr}, \mathrm{S}}=4.0 \times 10^{-4}$ obtained by Mayo analysis. This discrepancy may indicate that the conventional radical polymerization of MEA at low initiator concentrations (Figure 1c) is subject to chain transfer to monomer as well as to solvent (the Mayo plot is specifically designed to only "detect" chain transfer to solvent, whereas fitting of eq 2 "detects" chain transfer to all low MW species). The reason that chain transfer to monomer appears to be less significant for MEA in 1-propanol than 3-methyl-3-pentanol may be that $C_{\mathrm{tr}, \mathrm{S}}$ (Mayo) is considerably higher (factor of 3.5) for MEA in 1-propanol than in 3-methyl-3-pentanol, thus reducing the relative impact of chain transfer to monomer (which impacts analysis using eq 2).

\section{Nitroxide-Mediated Radical Polymerizations}

NMP initiated by a macroinitiator of relatively high MW can be a useful tool for studying chain transfer processes because chain transfer to low MW species is readily detected in the MW distributions as low MW tailing. In the case of a sufficiently high level of chain transfer to solvent, $M_{\mathrm{n}}$ may go through a maximum with increasing conversion. ${ }^{[2]} \mathrm{NMP}$ of TBAM initiated by poly $(t$ BA)-SG1 was carried out in the three different alcohol solvents: 3methyl-3-pentanol, 1-propanol, and 1-hexanol possessing a range of $C_{\mathrm{tr}, \mathrm{S}}\left(\right.$ Table 1). For all three alcohols, $M_{\mathrm{n}}$ initially increases with conversion indicative of a controlled/living system, but subsequently goes through a maximum at $60-75 \%$ conversion (depending on solvent), consistent with significant chain transfer to solvent (Figure 5). It is clear that the maximum attainable $\mathrm{MW}$ is dependent upon the magnitude of the $C_{\mathrm{tr}, \mathrm{S}}$ with the highest MW for the poly(TBAM) block achieved in 3-methyl-3-pentanol, which possesses the lowest $C_{\mathrm{tr}, \mathrm{S}}$. For all three solvents, the values of $M_{\mathrm{w}} / M_{\mathrm{n}}$ increase gradually with conversion, consistent with chain transfer to solvent occurring continuously (Figure 5).

Rather significant differences in polymerization rate $\left(R_{\mathrm{p}}\right)$ can be observed between the solvents in the corresponding conversion versus time data (Figure $\mathrm{S} 1$ ) with the highest $R_{\mathrm{p}}$ being obtained for 3-methyl-3-pentanol. It is well-known that the nature of the solvent can influence rate coefficients in radical polymerization ${ }^{[26]}$ - in the case of NMP the situation would be complex as solvent effects may be expected on both the fundamental rate coefficients of propagation and termination, as well as the rate coefficients associated with the NMP equilibrium ${ }^{[3]}$ - such a discussion goes beyond the scope of the present work. Suffice it to say that there is no correlation between $R_{\mathrm{p}}$ and the $C_{\mathrm{tr}, \mathrm{S}}$ values. 

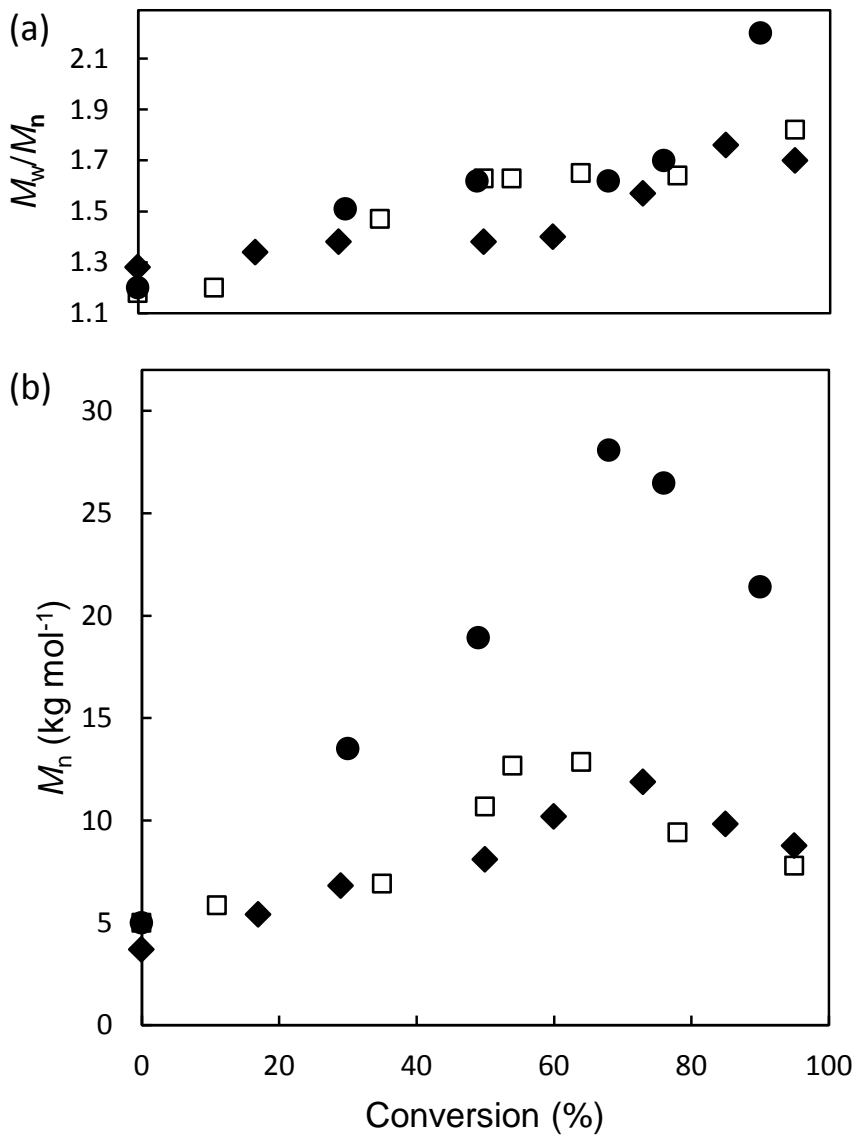

Figure 5. (a) $M_{\mathrm{w}} / M_{\mathrm{n}}$ and (b) $M_{\mathrm{n}}$ versus conversion plots of poly $(t$ BA)-SG1-initiated NMP of $2 \mathrm{M}$ TBAM at $120{ }^{\circ} \mathrm{C}$ with $25 \mathrm{~mol} \%$ excess free SG1 and $[\mathrm{TBAM}]_{0} /[\operatorname{poly}(t-\mathrm{BA})-\mathrm{SG} 1]_{0}=300$ in $3-$

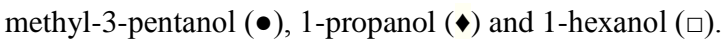

We began by carrying out the NMP of MEA using the bimolecular AIBN/SG1 system in 1-propanol with $[\mathrm{MEA}]_{0} /[\mathrm{AIBN}]_{0}=222$ and 444 at $120{ }^{\circ} \mathrm{C}$ (Figure 6). Up to about $60 \%$ conversion, an increase in the initiator concentration by a factor of two (i.e. $[\mathrm{MEA}]_{0} /[\mathrm{AIBN}]_{0}=222$ vs 444 with constant $\left.[\mathrm{AIBN}]_{0} /[\mathrm{SG} 1]_{0}\right)$ resulted in a decrease in $M_{\mathrm{n}}$ by close to a factor of two. The higher the targeted $M_{\mathrm{n}, \mathrm{th}}$, the higher is the probability that a given chain will undergo chain transfer during the polymerization, and thus $M_{\mathrm{n}}$ values begin to deviate from linearity at lower conversion ( 60 vs $\sim 70 \%$ conversion) and $M_{\mathrm{w}} / M_{\mathrm{n}}$ values are higher for the data set with the highest $M_{\mathrm{n}, \mathrm{th}}$. Replacing 1-propanol with 1-hexanol $\left([\mathrm{MEA}]_{0} /[\mathrm{AIBN}]_{0}=444\right)$ resulted in higher $M_{\mathrm{w}} / M_{\mathrm{n}}$ due to an increase in the size of the low MW tail (Figure S3), but $M_{\mathrm{n}}$ remained approximately linear with conversion up to $\sim 60 \%$ with a similar maximum $M_{\mathrm{n}}$ as for 1-propanol (Figure 6). The similar maximum
MW obtained in the two different linear alcohols supports the estimated similar $C_{\mathrm{tr}, \mathrm{S}}$ values from the above conventional radical polymerization Mayo data for MEA (Figure $3 \&$ Table 1). NMP of MEA was also conducted using poly(t-BA)-SG1 as macroinitiator in 3-methyl-3-pentanol (Figure 6) using the same conditions as for the NMP of TBAM (including identical [monomer]/[macroinitiator] ratios, Figure 5). This resulted in significantly lower maximum $M_{\mathrm{n}}$ in comparison to the NMP of TBAM in 3-methyl-3-pentanol, consistent with the higher $C_{\mathrm{tr}, \mathrm{S}}$ of MEA found using the above analysis of conventional radical polymerization data for this solvent.
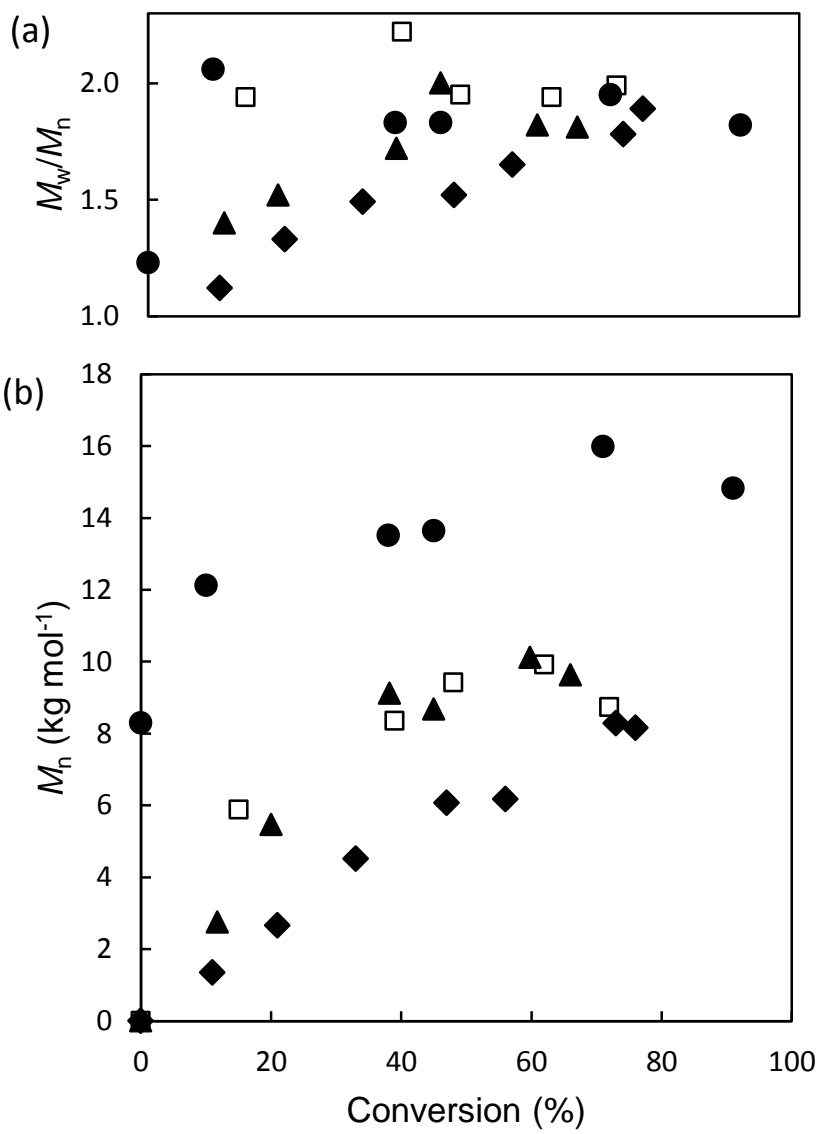

Figure 6. (a) $M_{\mathrm{w}} / M_{\mathrm{n}}$ and (b) $M_{\mathrm{n}}$ versus conversion plots for NMP of $2 \mathrm{M} \mathrm{MEA}$ at $120{ }^{\circ} \mathrm{C}$ : Bimolecular systems used $[\mathrm{SG} 1]_{0} /[\mathrm{AIBN}]_{0}=$ 2.5 and $[\mathrm{MEA}]_{0} /[\mathrm{AIBN}]_{0}=222(\diamond), 444(\boldsymbol{\Delta})$ in 1-propanol, and $[\mathrm{MEA}]_{0} /[\mathrm{AIBN}]_{0}=444$ in 1 -hexanol $(\square)$. Poly $(t-\mathrm{BA})-\mathrm{SG} 1$-initiated NMP (•) of MEA with 25 mol\% excess free SG1 in 3-methyl-3pentanol and $[\mathrm{MEA}]_{0} /[\operatorname{poly}(t-\mathrm{BA})-\mathrm{SG} 1]_{0}=300$. 
For both MEA and TBAM, there is an insignificant number of chains originating from spontaneous initiation in comparison to the number of chains from the macroinitiator or in situ generated alkoxyamine (previously reported for TBAM, ${ }^{[7]}$ and as verified for MEA in this work by heating MEA alone at $120{ }^{\circ} \mathrm{C}$ for various times (Figure S5)).

\section{CONCLUSIONS}

Chain transfer to solvent is shown to strongly influence the maximum attainable molecular weight in the conventional radical polymerization and NMP of two structurally diverse acrylamide monomers in various alcohol solvents. For polymerizations of TBAM, the propensity for chain transfer to solvent is shown to increase with the number of methylene units $\left(\mathrm{CH}_{2}\right)$ in the solvent with the highly branched alcohol, 3-methyl-3-pentanol (having fewer $\mathrm{CH}_{2} \mathrm{~s}$ ) giving the smallest $C_{\mathrm{tr}, \mathrm{S}}$ values (using Mayo analysis). Among the solvents investigated, 3-methyl-3-pentanol is thus recommended for solution NMP, since it allows the attainment of higher molecular weights. $C_{\mathrm{tr}, \mathrm{S}}$ values obtained from Mayo analysis (detecting only chain transfer to solvent) and analyses of conventional radical polymerizations at low initiator concentrations (that account for chain transfer to all small molecules), suggest that chain transfer to monomer may also be a significant end forming event for the polymerization of MEA in 3-methyl-3-pentanol. This is perhaps not surprising given the high number of $\mathrm{CH}_{2}$ units in this monomer (six saturated $\mathrm{CH}_{2} \mathrm{~s}$ versus two $\mathrm{CH}_{2} \mathrm{~s}$ in the alcohol solvent). Overall, the higher $C_{\mathrm{tr}, \mathrm{S}}$ values for MEA are consistent with the lower maximum $M_{\mathrm{n}}$ values in NMP in comparison to TBAM.

\section{ACKNOWLEDGEMENTS}

The authors are grateful to the Irish Research Council (formerly IRCSET) for a postgraduate scholarship award to C. Magee, as part of the first IUPAC Transnational Call in Polymer Chemistry, which was co-ordinated by F. Aldabbagh. The authors are grateful to $\mathrm{C}$. Elvira and M. Nash (CSIC, Madrid, Spain) for supplying MEA monomer.

\section{NOTES AND REFERENCES}

1 D. Kukulj, T. P. Davis and R. G. Gilbert, Macromolecules, 1998, 31, 994-999.
2 Y. Sugihara, P. O'Connor, P. B. Zetterlund and F. Aldabbagh, J. Polym. Sci., Part A: Polym. Chem., 2011, 49, 1856-1864.

3 J. Nicolas, Y. Guillaneuf, C. Lefay, D. Bertin, D. Gigmes and B. Charleux, Prog. Polym. Sci., 2013, 38, 63-235.

4 R. McHale, F. Aldabbagh, P. B. Zetterlund, H. Minami and M. Okubo, Macromolecules, 2006, 39, 6853-6860.

5 P. B. Zetterlund, Y. Saka, R. McHale, T. Nakamura, F. Aldabbagh and M. Okubo, Polymer, 2006, 47, 7900-7908.

6 R. McHale, F. Aldabbagh, P. B. Zetterlund and M. Okubo, Macromol. Chem. Phys., 2007, 208, 1813-1822.

7 O. Gibbons, W. M. Carroll, F. Aldabbagh, P. B. Zetterlund and B. Yamada, Macromol. Chem. Phys., 2008, 209, 2434-2444.

8 P. O'Connor, R. Yang, W. M. Carroll, Y. Rochev and F. Aldabbagh, Eur. Polym. J., 2012, 48, 1279-1288.

9 B. Lessard, C. Tervo and M. Maric, Macromol. React. Eng., 2009, 3, 245-256.

10 L. Couvreur, C. Lefay, J. Belleney, B. Charleux, O. Guerret and S. Magnet, Macromolecules, 2003, 36, 8260-8267.

11 G. Moad, E. Rizzardo and S. H. Thang, Aust. J. Chem., 2012, 65, $985-$ 1076.

12 J. Loiseau, N. Doeerr, J. M. Suau, J. B. Egraz, M. F. Llauro, C. Ladaviere and J. Claverie, Macromolecules, 2003, 36, 3066-3077.

13 L. B. De, M.-T. Charreyre, C. Chaix and C. Pichot, Polymer, 2005, 46, 623-637.

14 P. O'Connor, P. B. Zetterlund and F. Aldabbagh, J. Polym. Sci., Part A: Polym. Chem., 2011, 49, 1719-1723.

15 K. B. Doorty, T. A. Golubeva, A. V. Gorelov, Y. A. Rochev, L. T. Allen, K. A. Dawson, W. M. Gallagher and A. K. Keenan, Cardiovasc. Pathol., 2003, 12, 105-110.

16 O. Gibbons, W. M. Carroll, F. Aldabbagh and B. Yamada, J. Polym. Sci., Part A: Polym. Chem., 2006, 44, 6410-6418.

17 Y. Rochev, D. O'Halloran, T. Gorelova, V. Gilcreest, I. Selezneva, B. Gavrilyuk and A. Gorelov, J. Mater. Sci.: Mater. Med., 2004, 15, 513517.

18 D. Velasco, G. Rethore, B. Newland, J. Parra, C. Elvira, A. Pandit, L. Rojo and R. J. San, Eur. J. Pharm. Biopharm., 2012, 82, 465-474.

19 M. A. Mintzer and E. E. Simanek, Chem. Rev. (Washington, DC, U. S.), 2009, 109, 259-302.

20 R. Cuervo-Rodriguez, V. Bordege, M. C. Fernandez-Monreal, M. Fernandez-Garcia and E. L. Madruga, J. Polym. Sci., Part A: Polym. Chem., 2004, 42, 4168-4176.

21 S. Senel, N. Tokay, S. T. Camli and T. Hokelek, J. Mol. Struct., 2002, 642, 105-111.

22 P. O'Connor, P. B. Zetterlund and F. Aldabbagh, Macromolecules (Washington, DC, U. S.), 2010, 43, 914-919.

23 Y. Guillaneuf and P. Castignolles, J. Polym. Sci., Part A: Polym. Chem, 2008,46, 897-911

24 G. T. Russell, Am. Chem. Soc., Symp. Ser., (Washington, DC, U. S.), 2009, 1023, 15-31.

25 M. M. Alghamdi and G. T. Russell, Macromol. Chem. Phys., 2013 214, 1384-1395.

26 M. L. Coote, T. P. Davis, B. Klumperman and M. J. Monteiro, J. Macromol. Sci., Rev. Macromol. Chem. Phys., 1998, C38, 567-593. 